\title{
Evaluation of Microstructure Quality in Ductile Irons Based on Tensile Behaviour Analysis
}

\author{
Riccardo Donnini ${ }^{1, a}$, Franco Zanardi ${ }^{2, b}$, Federico Vettore $^{2, c}$, \\ Giuliano Angella ${ }^{1, \mathrm{~d}^{*}}$
}

${ }^{1}$ National Research Council of Italy (CNR) - Institute of Condensed Matter Chemistry and Technologies for Energy (ICMATE), Via R. Cozzi 53, 20125 - Milan, Italy

${ }^{2}$ Zanardi Fonderie S.p.A., Via Nazionale 3, 37046 - Minerbe (VR), Italy

ariccardo.donnini@cnr.it, bFR@zanardifonderie.com, 'cvfe@zanardifonderie.com, dgiuliano.angella@cnr.it

Keywords: Austempered ductile irons; isothermed ductile irons; tensile tests; constitutive equations; strain hardening

\begin{abstract}
Dislocation-density-related equations were proved to be promising tools to correlate tensile plastic behaviour and microstructure in ductile irons (DIs), revealing distinct relationships between equation parameters and microstructure features in austempered ductile irons (ADI) and isothermed ductile irons (IDI). These equations resulted to be successful also in the characterization of the austempering process through the plastic behaviour analysis of tensile tests of an ADI 1050 that was quenched at different times during austempering. The equation parameters could indeed be correlated to the time window for the best ausferrite, and could predict the precipitation of the deleterious $\varepsilon^{\prime}$ carbides for long austempering times. In the present work the results of the tensile plastic behaviour analysis of different DIs through dislocation-density-related equations are reported. The aim of the analysis was to test the capability of these equations to assess the microstructure quality of DIs and support their industrial production.
\end{abstract}

\section{Introduction}

Dislocation-density-related equations are constitutive equations with physical bases, where the flow stress $\sigma$ is related to the dislocation density $\rho[1,2]$. The strain hardening due to the increase of $\rho$ with straining is described by the mechanistic equations of strain hardening proposed by KocksMecking [3,4] and Estrin [4-6], and the parameters of these equations are intrinsically related to the microstructure of metallic materials. The most used dislocation-density-related equation is the Voce equation that was proved to be capable to correlate successfully tensile plastic behaviours and microstructures in a wide range of different ductile irons (DIs), namely austempered ductile irons (ADIs), isothermed ductile irons (IDIs) and ferritic-pearlitic DIs [7].

Recently it was reported that the dislocation-density-related Estrin equation could correlate the tensile plastic behaviour and the microstructure evolution of an ADI 1050 at different austempering times $[8,9]$, and that the evolution of the Estrin equation parameters with austempering times could identify the process window to produce the best ausferrite [8,9]. Depending on the grade, ADIs are produced through austenitization in the range of temperatures $800-920^{\circ} \mathrm{C}$, with subsequent holding in isothermal salt bath at temperatures typically between 250 and $400^{\circ} \mathrm{C}$ for the austempering transformation $[10,15] \gamma \rightarrow \alpha+\gamma_{\mathrm{HC}}$. Ausferrite consists of high volume fractions of Widmanstätten acicular laths of hard $\alpha$ ferrite, residual metastable soft $\gamma_{\mathrm{HC}}$ austenite that is rich in carbon, resulting in an optimal compromise between ductility and strength [10,16-17], and nodular graphite. However, for longer austempering times, the metastable $\gamma_{\mathrm{HC}}$ decomposes according to $\gamma_{\mathrm{HC}} \rightarrow \alpha+\varepsilon^{\prime}$, where $\varepsilon^{\prime}$ is a metastable Fe-C carbide that causes embrittlement [12,13]. If the alloy is quenched from austempering temperature after too short austempering times, a significant fraction of martensite is formed additionally to the $\alpha+\gamma_{\mathrm{HC}}$ structure. So the process window is the range of austempering times for which the austempering reaction is finished without formation of martensite and precipitation of carbides $\varepsilon^{\prime}$. The determination of this process window has economical relevance 
in ADI production, since in the best ausferrite conditions the ADIs satisfy the requirements for the optimal compromise of mechanical properties [18-24].

The present investigation aimed at determining a procedure based on tensile behaviour analysis to assess the DIs microstructure, and particularly ADI 1050. The assessment involved two steps: 1) definition of a diagram for the assessment of DIs microstructure quality based on Voce equation parameters resulting from tensile curve analysis; 2) definition of a diagram for the assessment of failure conditions related to possible material defects. Step 1 was performed through defining a Voce-parameters diagram that identified distinctly the plastic behaviours of DIs classes with different microstructures, and particularly could assess the microstructural evolution of an ADI 1050 produced during austempering (in-process assessment). Data from three batches of ADIs 1050 with different chemical compositions and heat treatments produced currently in Zanardi Fonderie S.p.A. were also reported on the diagram for between-processes assessment. Step 2 was satisfied for the different batches of ADI 1050 through a diagram to compare the experimental elongations to rupture with the ideal uniform elongations defined according to the Voce formalism.

\section{Materials and Experimental Methods}

Different DIs were tensile tested at room temperature with strain rate $10^{-4} \mathrm{~s}^{-1}$, complying to ASTM E8-8M. True stress $\sigma$ vs. true strain $\varepsilon$ data were considered, where $\sigma=S \cdot(1+e)$ and $\varepsilon=\ln (1+e)$, with $S$ and $e$ the engineering stress and strain, respectively. For the strain hardening analysis, the plastic component of flow curves was analysed, through considering only the plastic strain $\varepsilon_{p}=\varepsilon-\varepsilon_{e}$, with $\varepsilon_{e}=\sigma / E$ the elastic strain ( $E$ the experimental Young modulus).

For in-process assessment the plastic behaviour evolution of an ADI 1050 during austempering was analysed. The ADI 1050 with chemical composition complying to ISO 17804:2005(E) [25] and nodular graphite fraction of $10 \pm 1 \%$ was first austenitized, then held in salt bath at the austempering temperature for fourteen different increasing times $\left(t_{1}, t_{2}, \ldots, t_{14}\right.$ in arbitrary units) and then quenched. Detailed results on the tensile tests of the corresponding 14 samples are reported in $[8,9]$.

Other DIs produced in Zanardi Fonderie S.p.A. (complying to ISO 1083:2004/E [26] and Patent VR2006A000111-IDI-ITALIA [27]) were tensile tested to validate the capability of the proposed procedure for between-processes assessment: 3 batches of ADI 1050 with different chemical compositions and heat treatments for a total of 19 tensile tests; 5 tensile tests on ADIs 800; 4 on IDIs 800; 4 on IDIs 1000 and 14 on ferritic DIs. All tensile curves were fitted with Voce equation

$$
\sigma=\sigma_{V}+\left(\sigma_{o}-\sigma_{V}\right) \cdot \exp \left(-\frac{\varepsilon_{P}}{\varepsilon_{C}}\right)
$$

$\sigma_{V}$ is the saturation stress that is achieved asymptotically with straining, $\varepsilon_{c}$ is the characteristic transient strain that defines the rate with which $\sigma_{V}$ is approached, and $\sigma_{o}$ is the back-extrapolated stress to $\varepsilon_{p}=0$.

Though Voce equation could be fitted directly to flow curves, the correct procedure to find the Voce parameters based on their physical interpretation [3-6] implies the analysis of the strain hardening behaviour of materials, i.e. the differential data $\mathrm{d} \sigma / \mathrm{d} \varepsilon_{p}$ vs. $\sigma$, where $\mathrm{d} \sigma / \mathrm{d} \varepsilon_{p}$ is the strain hardening rate. The differential form of Eq. 1 is

$$
\frac{\mathrm{d} \sigma}{\mathrm{d} \varepsilon_{p}}=\Theta_{o}-\frac{\sigma}{\varepsilon_{C}} \quad \text { with } \quad \Theta_{o}=\frac{\sigma_{V}}{\varepsilon_{C}}
$$

There is a linear relationship between $\mathrm{d} \sigma / \mathrm{d} \varepsilon_{p}$ and $\sigma$, since $\sigma_{V}$ and $\varepsilon_{c}$ are considered constant during straining; therefore, if a linear region in the experimental strain hardening data is found, the Voce parameters $\varepsilon_{c}$ and $\Theta_{o}$ (and so $\sigma_{V}$ ) can be found. $\sigma_{o}$ in Eq. 1 is ultimately worked out by fitting Voce equation to the experimental flow curves $\sigma$ vs. $\varepsilon_{p}$.

The aim in the present investigation was not to approximate the most of the experimental flow curves, but to correlate tensile plastic behaviour and microstructure, which is possible by fitting the differential form of Voce equation (Eq. 2) to linear regions in the experimental differential data 
$\mathrm{d} \sigma / \mathrm{d} \varepsilon_{p}$ vs. $\sigma$ [3-9]. This correlation is indeed possible only at high stresses [3-9], since at low stresses a considerable part of the experimental differential data is usually not well described by Eq. 2, whilst excellent are the fits at high stresses where linear regions in the differential data $\mathrm{d} \sigma / \mathrm{d} \varepsilon_{p}$ vs. $\sigma$ are found in metallic materials, e.g. copper [3], stainless steel [28], cast irons [29] and DIs [7-9]. This discrepancy at low stresses in ductile materials like copper and stainless steels has been attributed to a transient of the dislocation structures evolution with straining [3, 28]. In DIs the interpretation of this discrepancy could be more complex, since the decohesion of the interface between graphite nodules and matrix (voids nucleation), voids growth and coalescence should have a significant role during deformation. However, it was found in ferritic DIs with a graphite nodule fraction of 13\% [30-32] that no dramatic drop of tensile stress occurred, though the damage fraction was achieved with straining at failure more than $20 \%$. In [32], where strain hardening was investigated in detail, it was reported that, though the effective stress softened in agreement with damage evolution, the back stress component related to microstructure heterogeneities slightly hardened, which compensated the effective stress reduction. This explained why the tensile stress did not dropped dramatically, and suggested that the tensile flow curves at high stresses are representative of the microstructure of DIs. Indeed, in the present investigations all DIs (fully ferritic and non-) that were tensile tested, presented linear regions at high stresses in the differential data $\mathrm{d} \sigma / \mathrm{d} \varepsilon_{p}$ vs. $\sigma$, so Voce equation (Eq. 2) was fitted to these regions to correlate tensile plastic flow and microstructure.

\section{Results and Discussion}

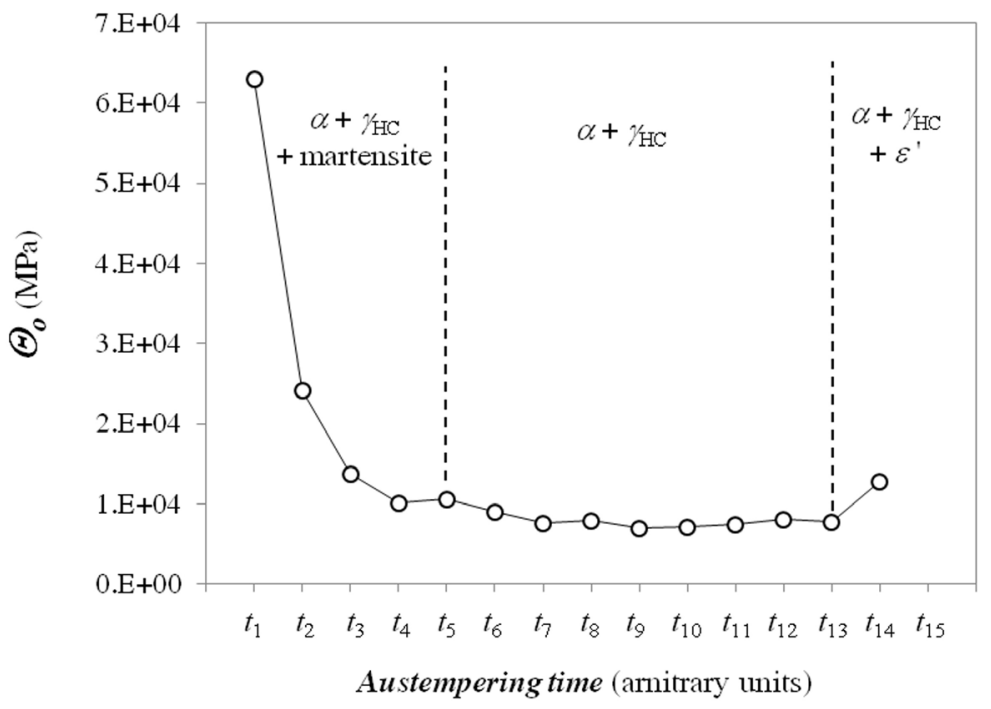

Figure 1 - Voce parameter $\Theta_{o}$ vs. austempering time for ADI 1050.

In Fig. 1 the Voce parameter $\Theta_{o}$ of Eq. 2 vs. the austempering time in arbitrary units for the investigated ADI 1050, is reported. The variation in $\Theta_{o}$ was $1-7 \%$, so error bars were not reported in the plot, since they had dimensions similar to the data symbols. The parameter $\Theta_{o}$ showed a wide low plateau between $t_{5}$ and $t_{13}$. Based on microstructure findings and plastic behaviour analysis reported in [9] the process window was associated to the interval $t_{7}-t_{11}$. The minimum corresponding to the austempering time $t_{9}$ was found to be the time for the best ausferrite with the coarsest and highest volume fraction of $\gamma_{\mathrm{HC}}$ without carbides $\varepsilon^{\prime}$ [9]. Before $t_{5}$ some martensite was found in the tensile tested samples, since the austempering reaction was not finished, whilst at $t_{14}$ transmission electron microscopy (TEM) observations found carbides $\varepsilon^{\prime}$ [9].

In Figs. 2 the Voce parameters $\Theta_{o}$ and $\varepsilon_{c}{ }^{-1}$ are reported against the austempering time focusing on the interval $t_{5}-t_{13}$. It is interesting to note that these trends are similar, suggesting that they are correlated. So the Voce parameters of Figs. $2 \mathrm{a}$ and $2 \mathrm{~b}$ are plotted on the same diagram (Fig.3), resulting in a linear relationship with an excellent square correlation coefficients $R^{2}$. 


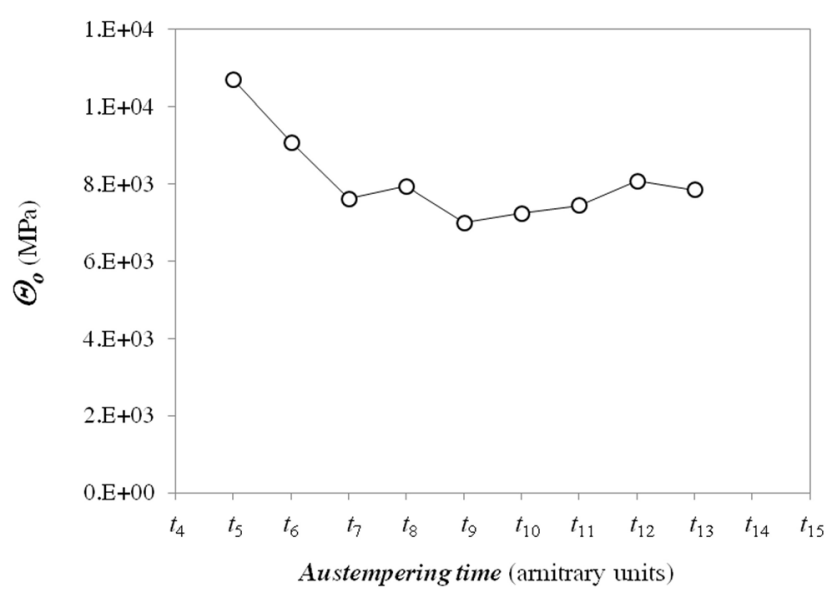

(a)

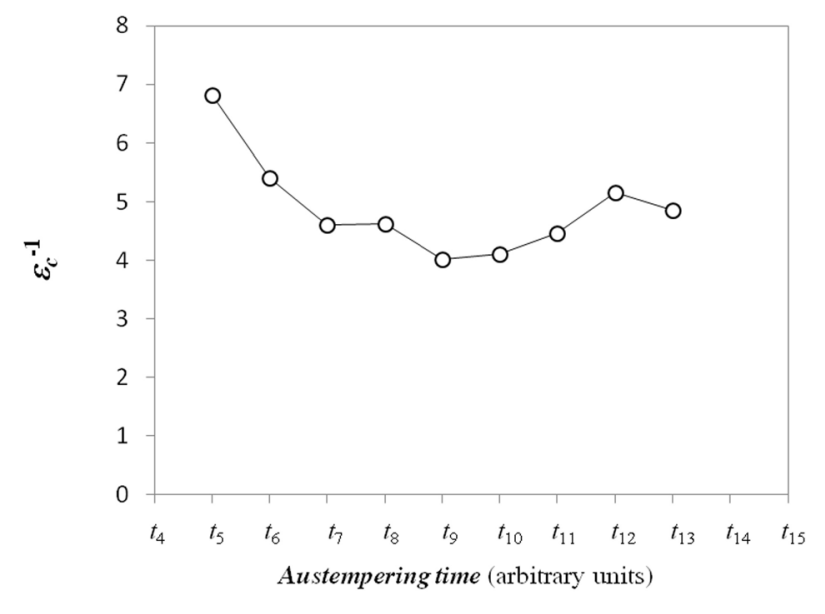

(b)

Figure 2 - a) Voce parameter $\Theta_{\mathrm{o}}$ vs. austempering time; b) Voce parameter $\varepsilon_{c}^{-1}$ vs. austempering time for ADI 1050.

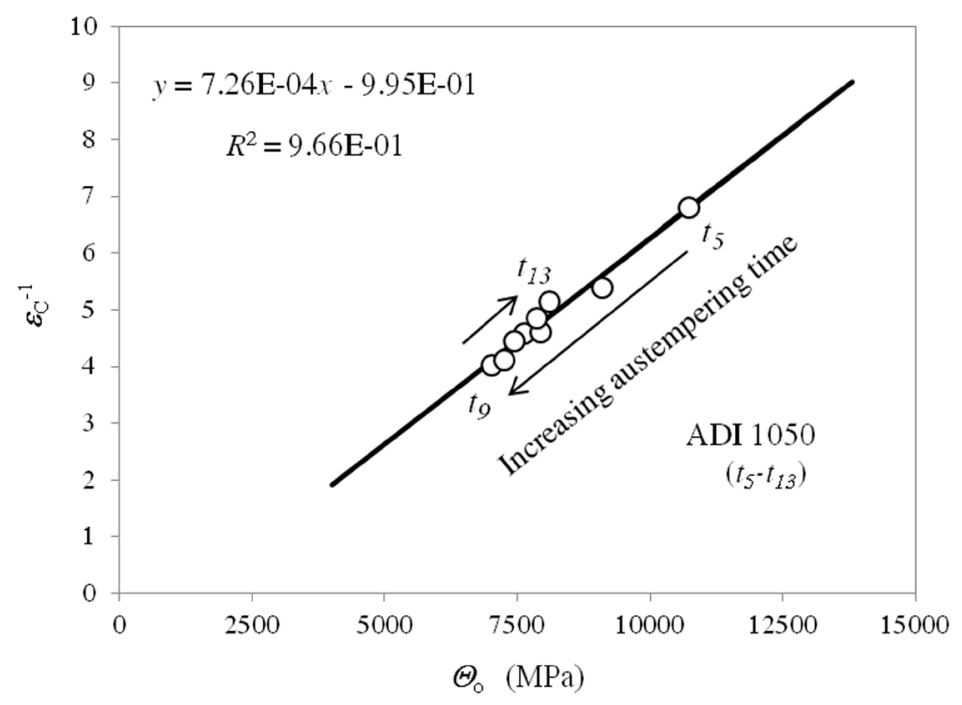

Figure 3 - Voce parameters diagram $\varepsilon_{c}^{-1}$ vs. $\Theta_{0}$. The arrows indicate increasing austempering times, from $t_{5}$ to $t_{13}$.

\section{In-process assessment}

The diagram in Fig. 3 can be adopted for the microstructure quality assessment of the ausferrite production during austempering. In fact the Voce parameters for ADI 1050 with good ausferrite (process window $t_{7}-t_{11}$ [9]) lie on the quality line close to the lowest data point corresponding to the austempering time $t_{9}$ for the best ausferrite $\left(\Theta_{o}=7003.2 \mathrm{MPa}, \varepsilon_{c}{ }^{-1}=4.02\right)$. In Fig. $4 \mathrm{a}$ the data points for austempering times shorter than $t_{5}$, when martensite was found after quenching, and $t_{14}$, where $\varepsilon^{\prime}$ carbides were observed through TEM [9], are reported. The data points from $t_{3}$ (with about $21 \%$ volume fraction of martensite) and $t_{14}$ lie close to the line, but significantly more far-away than data points $t_{5}$ and $t_{13}$. The data point from $t_{4}$ (with $18 \%$ volume fraction of martensite) is close to $t_{5}$, confirming that at the austempering time $t_{5}$ ausferrite in ADI 1050 was not established (although no martensite was present), in agreement with the process window that was found to be the interval $t_{7^{-}}$ $t_{11}[9]$. 


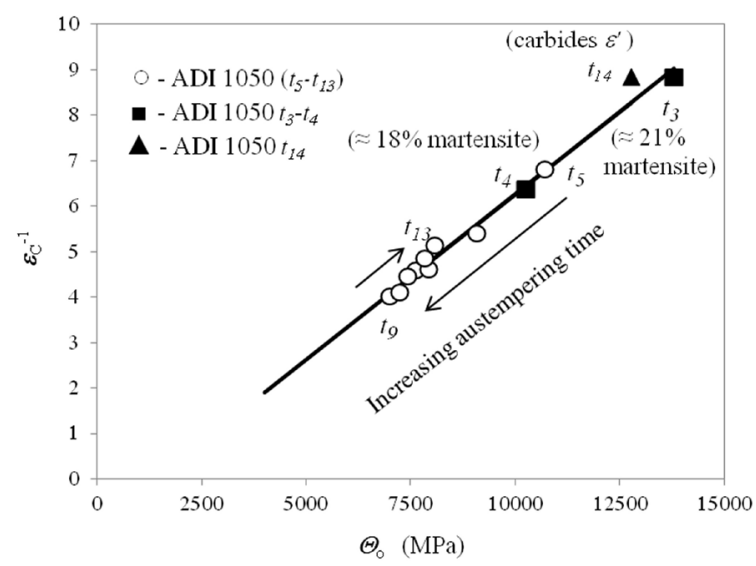

(a)

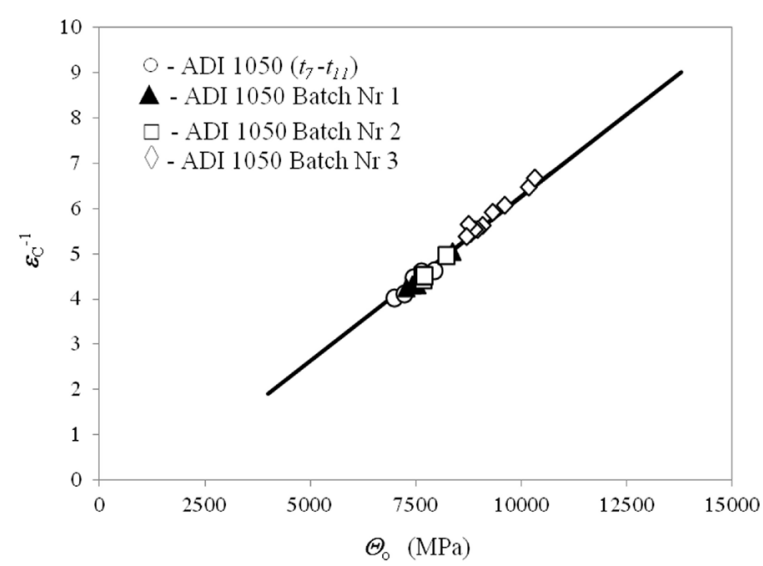

(b)

Figure 4 - a) Microstructure quality diagram for ADI 1050 production. Quality line is built with ADI 1050 data with austempering times between $t_{5}$ and $t_{13}$; data points from austempering times $t_{3}$ $\left(\approx 21 \%\right.$ martensite), $t_{4}\left(\approx 18 \%\right.$ martensite) and $t_{14}$ (precipitation of carbides $\varepsilon^{\prime}$ ) are also reported [9]. b) Microstructure quality diagram comparing different batches of ADI 1050 produced currently in Zanardi Fonderie S.p.A.

\section{Between-processes assessment}

The tensile flow curves of three different batches of ADI 1050 with different chemical compositions and heat treatments currently produced in Zanardi Fonderie S.p.A. were also analysed, and the Voce parameters were plotted in the quality assessment diagram in Fig. 4b. The same quality assessment line used in Fig. 4a was reported. It is noteworthy that the three batches data lie on the reference microstructure quality line, so a single quality line seems to identify the ADIs 1050 produced in Zanardi Fonderie S.p.A.. However, the different chemical compositions and austempering conditions affect the positions of the batches data on the ADI 1050 quality line: the original ADI 1050 and the batches Nr 1 and 2 have no differences, whilst the position of batch $\mathrm{Nr} 3$ is significantly higher. Though the results suggest that the microstructure quality assessment diagram could help ADI 1050 production, a larger amount of data have to be analysed to build up a microstructure quality diagram of ADI 1050 production more reliable on statistical bases.

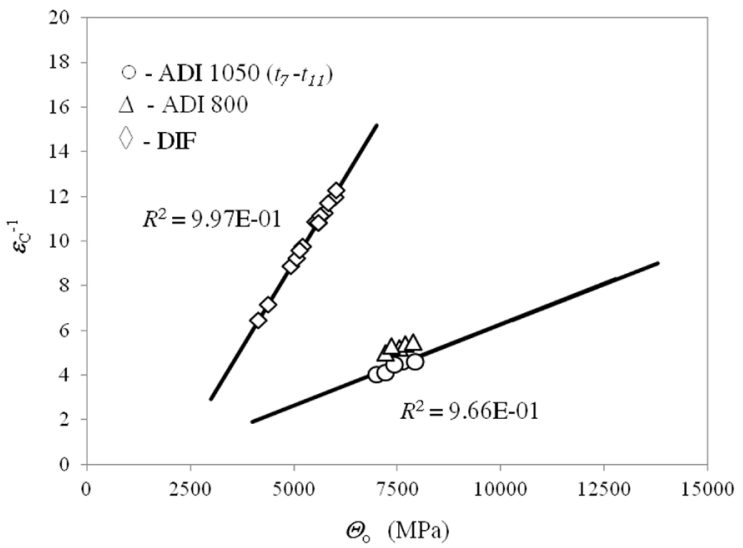

(a)

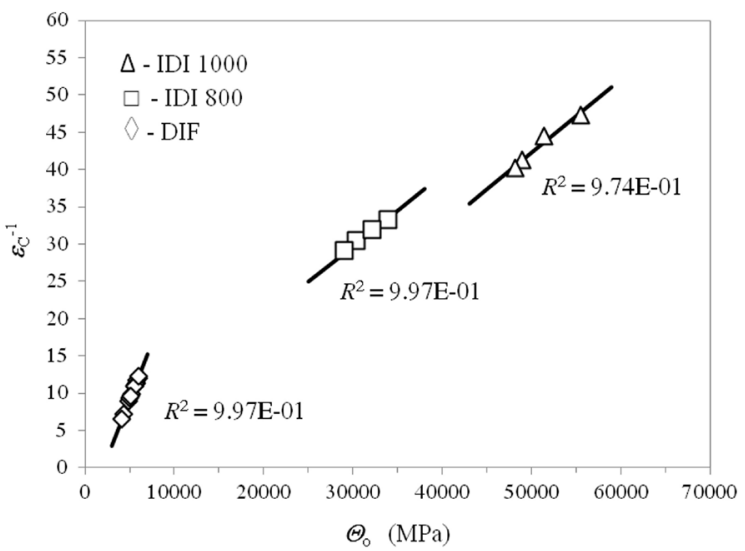

(b)

Figure 5 - a) Comparison of ADI 1050 with ADI 800; b) comparison of ADI 1050 with IDI 1000, IDI 800 and ferritic DI (DIF).

Voce parameters from different DIs were plotted in the microstructure quality assessment diagram to test the capability of the diagram to assess the microstructures of different materials. Voce data from ADI 800 and ferritic DIs (DIF) were reported in Fig. 5a and compared to ADI 1050, whilst Voce data from IDI 800, IDI 1000 and ferritic ductile irons (DIF) were reported in 
Fig. 5b. ADI 800 microstructure is similar to ADI 1050, with a higher volume fraction of metastable $\gamma_{\mathrm{HC}}$, so in Fig. 5a ADI 800 data are quite close to the ADI 1050 line, but clearly distinct. Also ferritic DIs have low Voce parameters, which is typical of the ductile alloys with small $\varepsilon_{c}{ }^{-1}$, and so propensity to high ductility. In Fig. $5 \mathrm{~b}$ for other DIs with significantly different microstructures, namely, perferrite in IDIs (ferrite + pearlite interconnected instead of having the conventional "bulls-eye" shape) and ferrite in DIF, the data lie on clearly distinct regions of the diagram, having their own microstructure quality lines. Exception is for ADI 800 in Fig. 5a, where little square correlation coefficient was found, so the best linear fit was not reported. More flow curves should be analysed.

\section{Failure assessment}

The Voce parameter $\varepsilon_{c}$ could give indications about the potential strains to rupture of the tensile tested materials, as higher $\varepsilon_{c}$ should give higher strains to rupture [7]. In fact, in the Voce formalism $\varepsilon_{c}$ is proportional to the uniform plastic strain $\varepsilon_{u}$ according to the relationship

$$
\varepsilon_{u}=\varepsilon_{c} \cdot \ln \left[\frac{\varepsilon_{c}+1}{\varepsilon_{c}} \cdot \frac{\sigma_{V}-\sigma_{o}}{\sigma_{V}}\right]
$$

$\varepsilon_{u}$ is the plastic strain that is achieved if the Considére's criterion is fulfilled, i.e. $\mathrm{d} \sigma / \mathrm{d} \varepsilon_{\mathrm{p}}=\sigma$, which is equivalent to $\mathrm{d} S / \mathrm{d} e=0$ in engineering data. However, the microstructure quality assessment diagrams based on Voce parameters (Figs. 4-5) assess the microstructure of materials that is related to the dislocation motion hindered on statistical bases by obstacles on the slip planes (interfaces, grain boundaries, precipitates, dislocation structures, etc.). Though plastic deformation brings lastly to failure, premature failure before the Considére's criterion is associated to the presence of metallurgical defects. So a different and complementary assessment for metallurgical defects and failure conditions is needed in order to complete the microstructure assessment of DIs.

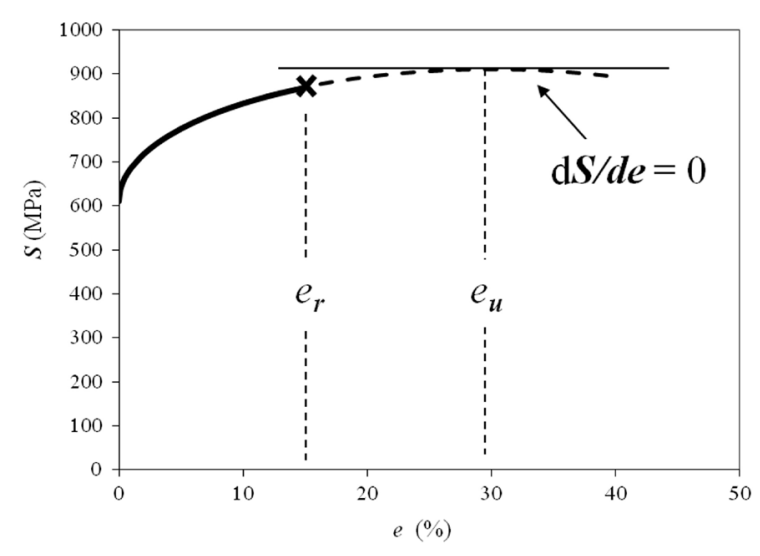

(a)

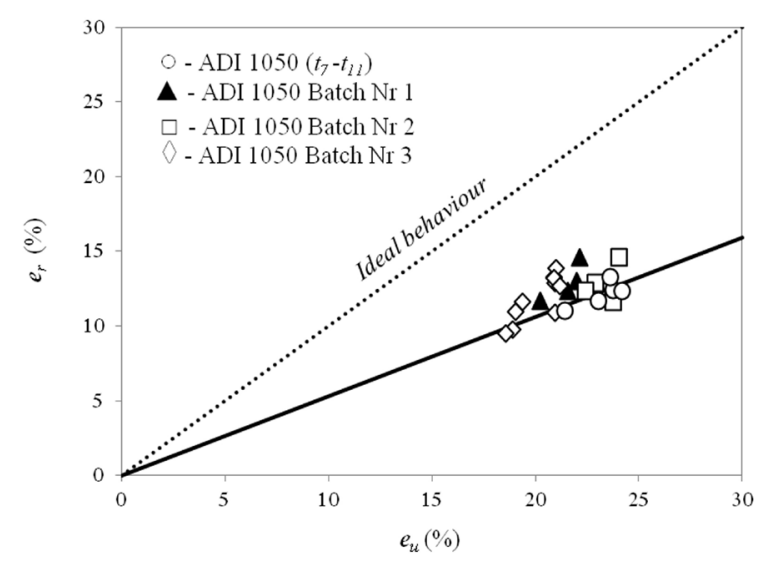

(b)

Figure 6 - a) Schematic representation of plastic uniform elongation $e_{u}$ for the Considére condition $\mathrm{d} S / \mathrm{d} e=0$ and premature plastic elongations to rupture $e_{r}$ in DIs. b) Comparison of experimental elongations to rupture $e_{r}$ with uniform elongations $e_{u}$ according to Eq.s 3 and 4 for different batches of ADI 1050.

The Considére condition $\mathrm{d} S / \mathrm{d} e=0$ identifies the beginning of necking in ductile materials like, for instance, steels. However in DIs necking does not occur or only at a little extent, so the Considére condition $\mathrm{d} S / \mathrm{d} e=0$ corresponds to the ultimate tensile stress with the best achievable elongation, namely the uniform elongation $e_{u}$, that hence represents a sort of ideal behaviour in DIs. However, metallurgical defects cause premature failures with plastic elongations to rupture $e_{r}<e_{u}$. In Fig. 6a a schematic representation of $e_{u}$ and $e_{r}$ is reported for sake of clarity. So for ADI 1050 a second diagram was introduced to compare the experimental plastic elongations $e_{r}$ with the ideal uniform plastic elongations $e_{u}$ calculated according to the Voce formalism in Eq. 3, that is

$$
e_{u}(\%)=\left[\exp \left(\varepsilon_{u}\right)-1\right] \cdot 100
$$


In Fig. $6 \mathrm{~b}$ the experimental plastic elongations $e_{r}$ are reported against the ideal uniform plastic elongations $e_{u}$. The reference line was found by considering the ADI 1050 data used in the previous diagrams. In Fig. $6 \mathrm{~b}$ the original ADI 1050 and batches $\mathrm{Nr} 1$ and 2 have similar failure behaviour, presenting similar $e_{u}$ and $e_{r}$. Batch $\mathrm{Nr} 3$ has clearly shorter $e_{u}$ and $e_{r}$ than the other batches. In conclusions, from the microstructure quality assessment diagram in Fig. $4 \mathrm{~b}$ and the failure assessment diagram in Fig. 6b, the original ADI 1050 and the batches $\mathrm{Nr} 1$ and 2 have equivalent microstructure, since they are mechanically equivalent. Batch 3 resulted to have slightly different plastic behaviour, and so microstructure will be investigated.

\section{Summary}

The aim of the present work was to introduced a procedure based on tensile behaviour analysis to assess the microstructure of different DIs. The assessment procedure comes into two steps:

1) definition of a Voce parameters diagram to assess the microstructure quality of DIs. The diagram can identify the interval of Voce parameters for the proper ausferrite production conditions in ADI 1050 (in-process production). Different batches of ADI 1050 with different chemical compositions and heat treatments currently produced in Zanardi Fonderie S.p.A. lie on the same quality line, assessing the correct production of ADI 1050 in term of consistent final results; different DIs have distinct regions with their own microstructure quality assessment lines (between-process assessment);

2) definition of a failure assessment diagram associable to the presence of metallurgical defects and based on the comparison between the experimental elongations to rupture with the ideal uniform elongations defined according to the Voce formalism.

The preliminary results here reported suggest that the proposed procedure can assess the microstructure and the production of ADI 1050 and different DIs. However, a larger amount of data should be used to build up more reliable assessment diagrams on statistical bases.

\section{References}

[1] U.F. Kocks, Laws for work-hardening and low-temperature creep, J. Eng. Mat. Tech. 98 (1976) 76-85.

[2] U.F. Kocks, H. Mecking, Kinetics of flow and strain-hardening, Acta Metall. 29 (1981) 18651875.

[3] U.F. Kocks, H. Mecking, Physics and phenomenology of strain hardening: the FCC case, Prog. Mater. Sci. 48 (2003) 171-273.

[4] Y. Estrin, Dislocation density related constitutive modelling in: Unified constitutive laws of plastic deformation, A.S. Krausz and K. Krausz Ed. (1996) 66-106.

[5] Y. Estrin, H. Mecking, A unified phenomenological description of the work hardening and creep based on one-parameter models, Acta Metall. 32 (1984) 57-70.

[6] Y. Estrin, Dislocation theory based constitutive modelling: foundations and applications, J. Mater. Process. Tech. 80-81 (1998) 33-39.

[7] G. Angella, F. Zanardi, R. Donnini, On the significance to use dislocation-density-related constitutive equations to correlate strain hardening with microstructure of metallic alloys: the case of conventional and austempered ductile irons, J. Alloys Compd. 669 (2016) 262-271.

[8] G. Angella, R. Donnini, F. Bonollo, A. Fabrizi, F. Zanardi, Assessment of austempering process evolution through tensile testing, La Metallurgia Italiana 6 (2017) 11-17.

[9] R. Donnini, A. Fabrizi, F. Bonollo, F. Zanardi, G. Angella, Assessment of the microstructure evolution of an austempered ductile iron during austempering process through strain hardening analysis, in Met. Mater. Int. 23 (2017) 855-864.

[10] J. Yang, S.K. Putatunda, Influence of a novel two-step austempering process on the strainhardening behaviour of austempered ductile cast iron (ADI), Mater. Sci. Eng. A 382 (2004) 265-279. 
[11]A. Basso, R. Martínez, J. Sikora, Influence of chemical composition and holding time on austenite $(\gamma) \rightarrow$ Ferrite $(\alpha)$ transformation in ductile iron occurring within the intercritical interval, J. Alloys Compd. 509 (2011) 9884-9889.

[12] J. Olofsson, D. Larsson, I.L. Svensson, Effect of Austempering on Plastic Behavior of Some Austempered Ductile Iron Alloys, Metall. Mater .Trans. A 42 (2011) 3999-4007.

[13] A. Meena, M. El Mansori, Material Characterization of Austempered Ductile Iron (ADI) Produced by a Sustainable Continuous Casting-Heat Treatment Process, Metall. Mater. Trans. A 43 (2012) 4755-4766.

[14] R.E. Smallman, I. R Harris, M. A. Duggan, Microstructure and materials processing, J. Mater. Process. Tech. 63 (1997) 18-29.

[15]H. Fredriksson, J. Stjerndahl, J. Tinoco, On the solidification of nodular cast iron and its relation to the expansion and contraction, Mater. Sci. Eng. A 413 (2005) 363-372.

[16] J. Dodd, High Strength, High Ductility Ductile Cast Irons, Mod. Cast. 68 (1978) 60-66.

[17] I. Schmidt, A. Schuchert, Unlubricated sliding wear of austempered ductile iron, Z. Metall. 78 (1987) 871-875.

[18] Y. J. Kim, H. Shin, H. Park, J. Lim, Investigation into mechanical properties of austempered ductile cast iron (ADI) in accordance with austempering temperature, Mater. Lett. 62 (2008) 357-360.

[19] M. H. Sohi, M. N. Ahmadabadi, A. B. Vahdat, The role of austempering parameters on the structure and mechanical properties of heavy section ADI , J. Mater. Process. Tech. 153-154 (2004) 203-208.

[20]J.L. Hernández-Rivera, R.E. Campos Cambranis, A. de la Garza, Study of microstructural evolution and mechanical properties exhibited by non alloyed ductile iron during conventional and stepped austempering heat treatment, Mater. Des. 32 (2011) 4756-4762.

[21] S. Panneerselvam, C.J. Martis, S.K. Putatunda, J.M. Boileau, An investigation on the stability of austenite in Austempered Ductile Cast Iron (ADI), Mater. Sci. Eng. A 626 (2015) 237-246.

[22]A. Basso, J. Sikora, R. Martinez, Analysis of mechanical properties and its associated fracture surfaces in dual-phase austempered ductile iron, Fatigue Fract. Eng. Mater. Struct. 36 (2013) 650-659.

[23] M. Soliman, A. Nofal, H. Palkowski, Alloy and process design of thermo-mechanically processed multiphase ductile iron, Mater. Des. 87 (2015) 450-465.

[24]D. O. Fernandino, J. M. Massone, R. E. Boeri, Characterization of the austemperability of partially austenitized ductile iron, J. Mater. Process. Tech. 213 (2013) 1801-1809.

[25] ISO 17804:2005(E), Founding - Ausferritic spheroidal graphite cast irons - Classification.

[26]ISO 1083:2004(E), Spheroidal graphite cast irons - Classification.

[27] Patent VR2006A000111-IDI-ITALIA.

[28] G. Angella, R. Donnini, D. Ripamonti, M. Maldini, Combination between Voce formalism and improved Kocks-Mecking approach to model small strains of flow curves at high temperatures, Mater. Sci. Eng. A 594 (2014) 381-388.

[29] M. Selin, Comparing Three Equations Used for Modeling the Tensile Flow Behavior of Compacted Graphite Cast Irons at Elevated Temperatures, Metall. Mater. Trans. A 41 (2010) 2805-2815.

[30] M.J. Dong, C. Prioul, D. Francois, Damage effect on the fracture toughness of nodular cast iron: Part I. damage characterization and plastic flow stress modeling, Metall Mater Trans A 28A (1997) 2245-2254.

[31]C. Guillemer-Neel, X. Feaugas, M. Clavel, Mechanical behavior and damage kinetics in nodular cast iron: Part I. Damage mechanisms, Metall Mater Trans A 31A (2000) 3063-3074.

[32] C. Guillemer-Neel, X. Feaugas, M. Clavel, Mechanical behavior and damage kinetics in nodular cast iron: Part II. Hardening and damage, Metall Mater Trans A 31A (2000) 30753086. 